\title{
English Writing Teaching based on Corpus
}

\author{
Xiuhui Hao \\ College of Foreign Languages, Bohai University, Jinzhou, 121013, China \\ gloryqiushi@163.com
}

Keywords: corpus; English writing teaching; teaching strategies; foreign language teaching

\begin{abstract}
Corpus is real language collection, to provide a valuable resource for writing, including grammar, language knowledge, reference standard, error analysis and evaluation, etc. Aiming at the common problems of the students' English writing, this article corpus' study provides scientific method for English writing teaching. First, the corpora and foreign language teaching; Then, corpus with foreign language teaching of writing; Finally, based on the corpus of English writing teaching strategies, including increasing language input in the process of teaching, cultivate the students' corpus retrieval ability, through analyzing the characteristics of the style to enhance students' language consciousness and cultivate students' autonomous learning ability, etc.
\end{abstract}

\section{Introduction}

English writing ability is five students' English language skills (listening, speaking, reading, writing and translating), one of the important aspects to cultivate students with strong English writing ability is one of the important tasks of English class teaching. Writing is still the weak link of English teaching at present, constantly sum up experience in teaching, analysis of students' English writing often make the mistake, in a timely manner to improve teaching methods, in order to improve the quality of English writing teaching is an important task of English writing teaching. "Outline of college English teaching for English majors", points out that the purpose of English writing course is to cultivate students' English writing ability, including the outline, articles, essays, and the simple practical writing. Course setting time according to the actual situation of universities, teaching content arrangement, from the perspective of the words and sentence structure, asked the students, according to the prompt composition or imitate model essay writing, or according to the certain situation of string, and then transition to paragraph writing skills, text layout and essay writing.

The level of English writing is the embodiment of the English comprehensive ability. The students' English writing is common problem: the ability to use words and phrases is poor, not enough attention to language information, a lot of words, specially predicate verbs, know what meaning is difficult to correctly in the sentences, some intransitive verbs need to match the prepositions are used together, many students but only single verb, so write sentences is often of mistakes; Single sentence changes, a lot of students in writing sentences are in the same sentence, length, the sentence pattern also is more "there be" structure, and all is the single order of subject, predicate, object and adverbial, the lack of change, boring to read; Poor logical paragraphs and articles, the traditional English teaching the language knowledge in the first place, ignored the textual structure of the article and paragraph development, so the students sense of written content is often the information is not strong, poor logic; Distinguish between sentence differences in both English and Chinese, English the sentence adverbial can act as by many ingredients, and the location is very flexible. Attributive modifier, and the use of the parenthesis are with the Chinese existence very big difference, but many students to organize the sentences according to Chinese usage; Writing less, due to the limited by class or the teaching content is overmuch, teaching is generally based on the reading is given priority to, little time for student writing, most teachers just simple explanation, give students after class to complete the writing content arrangement.

Corpus is large-scale electronic library by scientific sampling and processing, the text is the basis of corpus linguistics research resources, the research methods of empirical main resources. Since the advent of computerized corpus, the fast development of corpus linguistics, the use of corpus for 
language contrast research, the study of language ontology has achieved fruitful results in [1, 2]. Becker has created the world's first translational English corpus, put forward by using the parallel corpus, multilingual corpus and comparable corpus can be found and make sure it's difficult to find the semantic characteristics of the conventional methods, the research of the text style, language habits, such as the redundancy of language, word co-occurrence degree, form a coherent, syntactic pattern, specifications, and even the use of punctuation features, and help students to choose corresponding writing strategy. In this paper, based on the corpus study, offers a new solution for English writing teaching.

\section{Corpus and Foreign Language Teaching}

Corpus based on real language data, the characteristic of real objective. It introduces corpus in English teaching, can change the traditional teaching mode for middle school students' passive state and cultivate students' autonomous learning ability. Teachers are no longer just the imparter of knowledge, but a study guide. Under the guidance of teachers, students solve the problems in learning through the retrieval and analysis of large number of corpus. Corpus of authentic corpora and examples presented to learners has the characteristics of real directly. Students directly contact corpus, and use context semantic and summarizes the rule. The addition of corpus can also make the autonomous learning mode better reflect, retrieval and analysis of the corpus, the students belong to autonomous learning, teachers only need to do the necessary guidance and supervision. Corpus' relation with foreign language teaching is shown in Fig. 1.

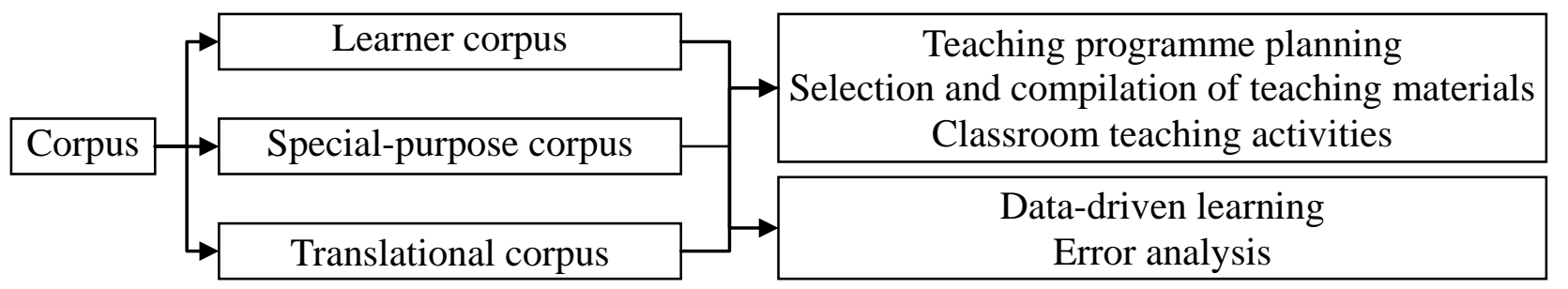

Fig. 1. Relationship on corpus and foreign language teaching

In Fig. 1, the Learner corpus, which is composed of a foreign language learners' written or spoken corpus, and used to analysis compared with native language learners' spoken and written language, so as to reveal the learners intermediary language structure and use of the characteristic; Special - purpose corpus to study language in specific domain or style, such as news, advertising, business, etc. In English teaching, special English corpus is widely used in the teaching of the academic English writing and speaking; Translational corpus, fast and reliable to find and verify some translation norms and universality, such as simplification, explication and conventionalization, overcome the subjectivity and randomness of translation studies.

Corpus is applied to foreign language mainly include three aspects of "Teaching programme planning, Selection and compilation of teaching materials, Classroom teaching activities". Would programme planning, before making outline, teachers can be associated with a specific classroom Teaching corpus analysis, to determine which is related to the target language domain language project, which developed to meet the requirements of actual classroom Teaching syllabus; Selection and compilation of teaching materials, good teaching material is the key to successful teaching, with the help of corpus, textbook writers can create based on the real example of practice, this will give students a chance to find the real characteristics of language use. Classroom teaching activities, corpus is such a tool, you can ask the learners to provide a large number of real and natural language materials, helping learners to our subjective initiative, autonomous learning. At the same time, due to the corpus collected real language materials, the applications of corpus to classroom teaching, learners can not only learn grammar knowledge, from the corpus of a large number of learned how to correctly use the language. 


\section{Corpus and English Writing Teaching}

English writing ability is an important part of English comprehensive ability, and is also one of the important content of English teaching. College English teaching requires students not only can sentence fluent coherence in writing, but also requires students able to use English more detailed and vivid description situation, attitude or emotion. So in English teaching, is to pay more attention to students' language accurate, is in line with the English expression habit. The application of corpus technology in English writing can make the students using corpus information changes to the thesis, the statistics out of the wrong type of writing, to cultivate the students' language awareness and autonomous learning ability. The corpus directly applied to the teaching of English writing way is data driven learning and error analysis, teachers and students in this way can make full use of the advantages of corpus.

(1) Data - driven learning is a kind of foreign language learning method based on corpus Data, put forward by Tim Johns, the main idea is the learner as a researcher, based on a lot of corpus Data observation, induction phenomenon of language use, words collocation self-discovery, rules of grammar and pragmatic features; Teacher as a guide, for learners learning resources, guide the learners to seek, to find the learning process, to cultivate learners' autonomous learning ability. Compared with the traditional foreign language teaching, data-driven study mainly has the following characteristics: first, through the index of corpus, with real corpus for language input; Second, with learners as the center, give priority to with autonomous learning; Third, summarizes the linguistic phenomenon from a large corpus, inductive learning as the core; Fourth, with the aid of bottom-up process of learning, cultivate the ability of exploration and discovery.

(2) Error analysis is refers to the study of second language learners' errors and analysis, the comparative analysis of being relatively limited replacement method. Error analysis of the theoretical basis of both its linguistics has its theoretical basis of psychology. Error analysis of the main claim is: many of the mistakes made by the second language learners, in addition to the influence of the first language, there are other factors. Error analysis of the literature often needs to distinguish between errors and mistakes in two concepts. Error is often caused by a lack of knowledge of learners, mistakes are caused by learners did not play out their own ability and make mistakes. According to the source of the error, error is often divided into interlingual errors and intralingual errors. Due to misuse and learners mother tongue has a common characteristic of language program called interlingual errors. Within the target language mistakes is called intralingual errors.

\section{Strategies of English Writing Teaching based on Corpus}

According to the characteristics of the teaching of English writing, with reference to relevant references [6-8], this paper puts forward the strategies as follows:

(1) Increase the language input in the process of teaching. Famous English scientist Krashen thinks, the human way of learning a language is to absorb the understandability of information process, as long as can get enough knowledge for the input, and is able to understand these input sex knowledge, so will be able to learn and use language. Therefore, language input is the first, and the output is second. At present the main problems existing in the teaching process, a large number of incorrect language input and input shortage problem. Second language learners to master the second language and can operate well, you must come into contact with the mass and the actual target language, or in the target language context, but the reality is not the case. In specific environment in second language learning is often unable to do, through the application of corpus can solve this problem obviously. Corpus contains abundant and authentic language material. Able to provide a variety of learning environment for learners of English, make up for the lack of a large number of target language input students' problems.

(2) Develop the students' ability of corpus retrieval. Corpus provides a personalized English writing tool to use effectively and you must learn to retrieve function. Mainly learn to retrieve 
chunk of highlighting features and the analysis of the corpus software functions. Collocation retrieval can be used to show the highlight features of corpus. If a language phenomenon in the corpus is high frequency, that is highlighted the characteristics of the language phenomenon. In writing teaching, the teacher by retrieving a highlight characteristics of language phenomenon, such as the commonly used words, words, sentence structure and discourse structure chart, etc., before writing training to the students, make students have a preliminary understanding, the pertinence, can improve students' retrieval so as to help students writing; Application of corpus software can analyze the language characteristics of the text. Linguistic features including the collocation of words, stylistic, grammatical features, semantic and pragmatic functions. Students deepen the understanding of a language phenomenon of actual method, is the use of corpus analysis function analysis of language. Teach students analyze long sentences, collocation, connection, type and tag ratio, ratio of content words and function words, consequent glossary and reverse statistical indicators such as vocabulary, so that the students from the perspective of a broader deepen the understanding of words.

(3) Enhance students' sense of style through analyzing the characteristics. Style research is an important part in the field of linguistics. The so-called style, is that people in the field of all kinds of social activities, according to different objects, different environment, which is formed by the use of language communication commonly used vocabulary, sentence structure, rhetoric and a series of characteristics of language use. In real life, according to the different language environment to communicate language effectively, not only involves the content, but also relating to the language itself, involving language means of expression, the combination of material and so on the accuracy of the choice. Therefore, language learning is closely linked social communication environment in modern linguistics to study language variability law a branch discipline. English writing teaching process, teachers should make full use of corpus widely collected all kinds of writing material, through self-built small corpus, adopt the method of combination of theory and examples, to let the students through the analysis, to observe and understand the characteristics of the different styles of discourse, through the interaction between language and context building discourse to achieve communicative purposes, and the different style paper summarizes types of stylistic meaning, cultivate the students' sense of style.

(4) Develop the students' ability of autonomous learning. Autonomous learning is corresponding with the traditional accepting study a kind of modern learning style. Take the student as the main body of learning, the students themselves, not controlled by the others, undisturbed by reading, listening, study, observation and practice means that individuals can get continuous change (knowledge and skills, the method and process, the improvement of emotion and value and sublimation) behavior. Based on the corpus approach to learning can cultivate the students' learning autonomy, and to know and solve problems independently. Because learning process based on corpus is based on students as the center, to the students present language facts, encourage students through the analysis of the language of practical application examples, found that the language characteristics of the target language and summarize its regularity, language awareness improved significantly, improve language internalization degree. The "discovery" study method to make learning is no longer limited to the classroom. Once the mastery of the skills, can at any time using retrieval tools, solve all kinds of questions encountered in the learning, to achieve the purpose of autonomous learning.

\section{Conclusion}

Based on the corpus of English writing is a new attempt to English writing teaching mode, has a practical significance. First, the teaching goal more clearly, to explore the new way to improve the students English writing ability, enhance writing accomplishment, and communication lays the foundation for the future; Second, advanced teaching methods, based on large data corpus and the modern education technology aided teaching of English writing, rich teaching resources, science teaching process; Third, the teaching idea is novel, with "task as the main line, teacher as the leading factor, the student as the main body of English writing teaching, give full play to the 
initiative and creativity of students in the teaching process, cultivate students' autonomous learning ability; Fourth, the teaching arrangement in line with the actual, advanced teaching of English writing teaching method system, solved the English writing in the English teaching position is not clear, time is not enough and the content is not specific. This article research results to improve their written expression ability, cultivate solid fundamental English writing have to effect, provide a scientific method to improve the quality of English writing teaching.

\section{References}

[1] Velislava Stoykova. Teaching Corpus Linguistics[J]. Procedia - Social and Behavioral Sciences. 2014, 143(8): 437-441.

[2] Blanka Frydrychova Klimova. Using Corpus Linguistics in the Development of Writing[J]. Procedia - Social and Behavioral Sciences. 2014, 141(1): 124-128.

[3] J. M. Pu, "A Study of the Teaching Mode for Corpus-Based English Writing," Education and teaching research, vol. 23, no. 6, pp. 70-73, 2009.

[4] B. Xiang, H. Ma, "Application of corpus in English writing teaching," Journal of Chongqing, vol. 11, no. 5, pp. 148, 2015.

[5] Y. Zhu, "Application of corpus in the teaching of English writing," Foreign Language World, vol. 30, no. 3, pp. 24-31, 2009.

[6] X. H. An, "Review and Prospect on the application of corpus in the teaching of foreign language writing," Journal of Xi'an International Studies University, vol. 21, no. 2, pp. 54-58, 2013.

[7] W. L. Zi, J. P. Guo, "Application of the Corpus Retrieval Tool to the Teaching of English," Theory and Practice of Education, vol. 33, no. 24, pp. 54-56, 2013.

[8] Q. Huang, "Analysis of the application of self built corpus in College English writing instruction," Journal of Mudanjiang College of Education, vol. 34, no. 5, pp. 79-80, 2016. 